\title{
Bacterial lactase genes diversity in intestinal mucosa of dysbacterial diarrhea mice treated with Qiweibaizhu powder
}

\author{
Chengxing Long ${ }^{1,2} \cdot$ Yawei Liu ${ }^{1} \cdot \mathrm{Lu} \mathrm{He}^{1} \cdot$ Rong Yu$^{1} \cdot$ Dandan $\mathrm{Li}^{1} \cdot$ Zhoujin Tan $^{1} \cdot$ Huaying Hui ${ }^{1}$
}

Received: 24 May 2018 / Accepted: 24 September 2018 / Published online: 27 September 2018

(c) Springer-Verlag GmbH Germany, part of Springer Nature 2018

\begin{abstract}
The current research tried to investigate the effect of Qiweibaizhu powder (QWBZP) on intestinal mucosa bacterial lactase gene from dysbacterial diarrhea mice, as the good therapeutic mechanism of QWBZP on antibiotics-induced diarrhea. Dysbacterial diarrhea mice model was constructed by gastric perfusion with mixture of cephradine capsules and gentamicin sulfate $\left(23.33 \mathrm{~mL} \mathrm{~kg}^{-1} \mathrm{day}^{-1}\right)$ for 5 days. After the success of establishing diarrhea, the mice in treatment group were gavaged with QWBZP for 3 days. Intestinal mucosa in each group was collected, and diversity of bacterial lactase genes in intestinal mucosa of mice was carried out by Miseq metagenome sequencing. The results showed the Chao1, ACE, Simpson and Shannon indices in treatment group were lower than model group and were similar to control group. The same result was obtained from the operational taxonomic units (OTUs). There were 298, 435 and 254 OTUs in the control group, model group and treatment group, respectively. Principal component analysis (PCA) indicated that samples distribution in both normal and treatment groups were relatively intensive, distances among individuals were small, while opposite results were observed in model group. Moreover, antibiotics increased the diversity and abundance of bacterial lactase genes at phylum and genus levels. However, they decreased and were similar to control group after treating with QWBZP. Our results indicate that QWBZP has a positive effect on the recovery of bacterial lactase gene diversity to normal level. In addition, QWBZP increase the abundance of Lysobacter and Eukaryota.
\end{abstract}

Keywords Qiweibaizhu powder $\cdot$ Dysbacterial diarrhea $\cdot$ Intestinal mucosa $\cdot$ Lactase gene $\cdot$ Diversity $\cdot$ Antibiotics

\section{Introduction}

Lactase, a disaccharidase also known as $\beta$-galactosidase, widely present in the mammalian intestinal mucosa microvilli surface, can hydrolyze lactose into two easily soluble monosaccharides, namely glucose and galactose, and play a key role in lactose digestion and absorption (Carter and Attel 2013; Ruchkina et al. 2013; Vandenplas 2015). Human and animal lactase are mainly secreted by intestinal mucosa, distributed in the intestinal contents and mucosa,

Zhoujin Tan

tanzhjin@sohu.com

Huaying Hui

huihuaying2003@126.com

1 Hunan University of Chinese Medicine, Xueshi Road, Yuelu District, Changsha 410208, Hunan, China

2 College of Mathematics and Finance, Hunan University of Humanities, Science and Technology, Loudi, 417000 Hunan, China and mucosal lactase is the main source of intestinal lactase (Wiecek et al. 2014; Sun et al. 2015). Intestinal lactase is encoded and translated from lactase gene, and its activity level is controlled by genes. Microorganisms are the main source of lactase-producing, many intestinal bacteria also produce lactase by fermentation, such as Escherichia coli, Lactobacillus sp., Bifidobacterium sp., Bacillus sp. (Rhimi et al. 2009; Juajun et al. 2011; Ma et al. 2017). Clinically, the patients with symptoms of abdominal distension, borborygmus and diarrhea associated with lactase deficiency (LD) or the decrease of lactase activity show an increasing trend.

In addition to the physiological decrease associated with age, Mammalian lactase activity is also related to a variety of factors (Tran et al. 2011). Studies have shown that antibiotics can inhibit and damage intestinal lactase activity leading to diarrhea (Peng and Ren 2011). And diarrhea is often accompanied by dysbacteriosis (Liu and Sun 2014; Cao et al. 2017). Our previous study also showed that antibiotics reduced the diversity of bacterial lactase gene and changed its community structure in intestinal contents (Long et al. 
2017b). As an important part of mucosa, microorganisms may affect the activities of lactase.

Starting from the whole, traditional Chinese medicine has the potential advantage of regulating the function of spleen or stomach and the immunity of the body, and restoring the intestinal microbiota. It can directly or indirectly regulate intestinal microbiota and improve various intestinal enzyme activities because of its rich chemical component and wide pharmacological effects (Yao et al. 2012; Ma et al. 2014; He et al. 2017a). For example, compound radix pulsatillae can significantly enhance intestinal mucosal lactase activity in diarrhea mice, indicating that the therapeutic mechanism of pulsatillae on diarrhea may be related to the regulation of lactase activity (Zhang et al. 2010). Sijunzi Decoction can improve lactase activity in mice and play an important role in the mechanism of treating diarrhea (Zhang et al. 2009).

QWBZP is a millennium ancient prescription to treat various diarrheas and intestinal diseases with significant effect (Peng et al. 2014). Modern pharmacological studies and clinical practice have shown that QWBZP can significantly regulate intestinal microbiota of mice with dysbacteriosis, and has a good repair effect on the small intestine mucosal structure, but it does not increase the diversity of bacterial lactase gene in the intestinal contents, its curative effect on diarrhea mainly relevant to some key lactase-producing strains (Tan et al. 2013; Zhang et al. 2013; He et al. 2017b).

Compared with the intestinal contents, mucous has many advantages, such as completed in structure, sound in selfimmune, stable in flora, and less affected by the external environment. In this study, we aimed to investigate the impact of QWBZP on the diversity of bacterial lactase genes in intestinal mucosa and further explored the curative effect of QWBZP on dysbacterial diarrhea induced by antibiotics.

\section{Materials and methods}

\section{Materials}

\section{Animals}

Eighteen one-month-old Kunming mice with license number SCXK (Xiang) 2013-0004 were purchased from Hunan Slaccas Jingda Laboratory Animal Company (Hunan, China). All procedures involving animals were performed according to the protocols approved by the Institutional Animal Care and Use Committee of Hunan University of Chinese Medicine.

\section{Reagents}

Cephradine capsules (batch number: 151101) were purchased from Suzhou Chung-Hwa Chemical and
Pharmaceutical Industrial Co., Ltd. Gentamicin sulfate injection (batch number: 5150307) was purchased from Yichang Humanwell Pharmaceutical Co., Ltd. Prepared as an antibiotic mixture at a concentration of $62.5 \mathrm{~g} \mathrm{~L}^{-1}$ with sterile saline according to the ratio of $1: 2$, and stored at $4{ }^{\circ} \mathrm{C}$ (Xiao et al. 2015). Solutions such as lysozyme, protease $\mathrm{K}$, Tris-saturated phenol-chloroform-isoamyl alcohol (25:24:1) and TE buffer were purchased from Beijing Dingguo Changsheng Biotechnology Co., Ltd. Other solutions such as CTAB/NaCl, $5 \mathrm{~mol} \mathrm{~L}^{-1} \mathrm{NaCl}, 0.1 \mathrm{~mol} \mathrm{~L}^{-1}$ PBS buffer and $10 \%$ SDS were prepared in the laboratory.

\section{Medicine}

According to the Chinese Pharmacopoeia 2010, QWBZP was composed of ginseng $6 \mathrm{~g}$, costustoot $6 \mathrm{~g}$, poriacocos $10 \mathrm{~g}$, roasted rhizome atractylodes macrocephalae $10 \mathrm{~g}$, pueraria $10 \mathrm{~g}$, agastache $10 \mathrm{~g}$ and liquarice $3 \mathrm{~g}$. Which were purchased as prescription from the first hospital of Hunan University of Chinese Medicine. Weighing appropriate medicine according to the above ratio and soaking the medicine for half an hour covered with cold water, decocting the medicine with big fire until it boils, then with soft fire, decoction twice and each time for $20-30 \mathrm{~min}$. The two times liquid medicine should be mixed to make $100 \%$ dose of traditional decoction of QWBZP and frozen at $4{ }^{\circ} \mathrm{C}$ for following experiment (Zhang et al. 2014).

\section{Methods}

The mice (equal number of male and female) were randomly divided into three groups: control group (tlcm), model group (tlmm) and treatment group (tlqm), six mice (three males and three females) in each group after 2 days of adaptive feeding. The mice in both model group and treatment group were administered $0.35 \mathrm{~mL}$ antibiotics mixture composed of gentamycin sulfate and cefradine $\left(23.33 \mathrm{~mL} \cdot \mathrm{kg}^{-1} \cdot \mathrm{day}^{-1}\right)$. Correspondingly, the mice in control group were gavaged with $0.35 \mathrm{~mL}$ sterile water, twice a day for 5 days (Zeng et al. 2012). When symptoms (specifically watery stool, declined activity, curled up, arched back trembling and poor appetite) were induced in mice, it indicated the success of establishing diarrheal model. Then, the mice in the treatment were administered QWBZP decoction at the dose of 0.16 $\mathrm{g} \mathrm{kg}^{-1}$ day $^{-1}$ for 3 days (Guo et al. 2015). On a sterile operation platform, mice were sacrificed using cervical vertebra dislocation. Then, intestinal mucosa was scraped with cover slips and added 2 times weight of saline after squeezing out the chymus, cutting open the intestinal tract and cleaning the intestinal wall with saline. Finally, intestinal mucosa samples of each two mice (one male and one female) in every group were selected and immediately frozen at $4{ }^{\circ} \mathrm{C}$ for following experiment (Jin et al. 2012). 


\section{Metagenome extraction}

According to our previous report, metagenome DNA from the intestinal mucosa microorganism was extracted by the following protocols (Wu et al. 2012). $2.0 \mathrm{~g}$ of intestinal mucosa was collected in a sterile environment, placed in a germ-free centrifuge tube and homogenized in $5 \mathrm{~mL}$ of $0.1 \mathrm{~mol} \mathrm{~L}^{-1}$ phosphate buffer solution (PBS), then centrifuged at $200 \times g$ for $2 \mathrm{~min}$. After washing twice with PBS, the supernatant was transferred into new germ-free tubes and centrifuged at $10,000 \times g$ for $8 \mathrm{~min}$. Then, the new sediments were gathered, washed once with PBS, twice with acetone, and three times with PBS, then resuspended in $4 \mathrm{~mL} \mathrm{TE}$ buffer. After sample pretreatment, $500 \mu \mathrm{L}$ of suspension was added with $20 \mu \mathrm{L}$ lysozyme, $5 \mu \mathrm{L}$ proteinase $\mathrm{K}$, and $45 \mu \mathrm{L}$ TE buffer, and homogenized in $1.5 \mathrm{~mL}$ germ-free EP tubes. Samples were incubated at $37{ }^{\circ} \mathrm{C}$ for $30 \mathrm{~min}$, and mixed with $30 \mu \mathrm{L}$ of $10 \%$ SDS, followed by incubation at $37{ }^{\circ} \mathrm{C}$ for $40 \mathrm{~min}$, with vortexing once every $10 \mathrm{~min}$. Afterwards, $80 \mu \mathrm{L}$ of $\mathrm{CTAB} / \mathrm{NaCl}$ and $100 \mu \mathrm{L}$ of $5 \mathrm{~mol} \mathrm{~L}^{-1} \mathrm{NaCl}$ were added and mixed well. The mixture was vortexed at $65^{\circ} \mathrm{C}$ for $10 \mathrm{~min}$. An equal volume of Tris-saturated phenol-chloroform-isoamyl alcohol (25:24:1) was then added to the sample, mixed well and centrifuged at $10,000 \times g$ for $3 \mathrm{~min}$. The supernatant was transferred into new germ-free tubes, mixed with an equal volume of chloroform-isoamyl alcohol (24:1), centrifuged at $10,000 \times g$ for $3 \mathrm{~min}$. The supernatant was transferred into fresh germ-free tubes, and an equal volume of chloroform-isoamyl alcohol (24:1) was added and mixed well again. The supernatant was transferred into fresh germ-free tubes after centrifugation at $10,000 \times g$ for $3 \mathrm{~min}, 10^{-1}$ volume of $3 \mathrm{~mol} \mathrm{~L}^{-1}$ sodium acetate and double volume of absolute ethyl alcohol were added, and precipitated at $-20^{\circ} \mathrm{C}$ for about $12 \mathrm{~h}$. Samples were centrifuged at $10,000 \times g$ for $3 \mathrm{~min}$. The acquired sediment were washed with $70 \%$ ethanol, dried and eventually dissolved in $50 \mu \mathrm{L}$ TE buffer for DNA metagenome extraction.

\section{PCR amplification of intestinal bacterial lactase gene and Miseq metagenome sequencing}

Primers were designed for PCR amplification based on the conserved region of the $\beta$-galactosidase gene nucleotide sequence of Escherichia coli and Lactobacillus from NCBI. The forward primer was 5'-TRRGCAACGAAT ACGGSTG-3' and the reverse primer was 5'-ACCATG AARTTSGTGGTSARCGG-3'. Universal primers were designed and synthesized by Shanghai Personal Biotechnology Co., Ltd. PCR mixture $(25 \mu \mathrm{L})$ contained $5.0 \mu \mathrm{L}$ $5 \times$ reaction buffer, $5.0 \mu \mathrm{L} 5 \times \mathrm{GC}$ buffer, $0.5 \mu \mathrm{L} 10 \mathrm{mmol}$ $\mathrm{L}^{-1}$ dNTP, $1.0 \mu \mathrm{L} 10 \mu \mathrm{mol} \mathrm{L}{ }^{-1}$ forward primer, $1.0 \mu \mathrm{L}$ $10 \mu \mathrm{mol} \mathrm{L}{ }^{-1}$ reverse primer, $1.0 \mu \mathrm{L}$ DNA template, 11.25 $\mu \mathrm{L}$ sterilized $\mathrm{ddH}_{2} \mathrm{O}, 0.25 \mu \mathrm{L}$ Q5 high-fidelity DNA polymerase. PCR conditions were as follow: initial denaturation at $98{ }^{\circ} \mathrm{C}$ for $30 \mathrm{~s}$, followed by 32 cycles at $98{ }^{\circ} \mathrm{C}$ for $15 \mathrm{~s}$, annealing at $46^{\circ} \mathrm{C}$ for $30 \mathrm{~s}$, extension at $72{ }^{\circ} \mathrm{C}$ for $30 \mathrm{~s}$, and then $72{ }^{\circ} \mathrm{C}$ for $5 \mathrm{~min}$ and holding at $4{ }^{\circ} \mathrm{C}$ (Long et al. 2017a). Miseq metagenome sequencing was completed by Shanghai Personal Biotechnology Co., Ltd.

\section{Bioinformatics and statistical analysis}

The abundance and diversity of bacterial lactase genes in the intestinal mucosa were measured by alpha diversity analysis which contained Chao1, ACE, Simpson, and Shannon indices based on the operational taxonomic units (OTUs) (Mahaffee and Kloepper 1997; Shannon 1997; Pitta et al. 2010, 2014). Principle component analysis (PCA) (Ramette 2007) and Hierarchical clustering (HC) were used to analyze the main distribution characteristics and the similarity of community samples. The SPSS 21.0 software (IBM Corp, Armonk, NY, USA) was used to analyze the measurement data. Pairwise samples $t$ test was applied to compare the statistical significance of differences, with $P<0.05$ or $P<0.01$.

\section{Results \\ Effects of QWBZP on bacterial lactase genes diversity in the intestinal mucosa}

To investigate the impact of QWBZP treatment on dysbacterial diarrhea, the alpha diversity analysis was estimated. The results showed that Chao1, ACE, Simpson and Shannon indices were higher in the model group than those both in control and treatment groups. Among them, there was significant difference in Simpson index (Fig. 1; $P<0.05$ ), which indicated that antibiotics increased the diversity of bacterial lactase genes in the intestinal mucosal community. After treatment with QWBZP, we found that Chao1, ACE, Simpson and Shannon indices were similar to the normal group, and there is no significant difference $(P>0.05)$, which suggests that QWBZP helps the recovery of mucosal bacteria lactase genes diversity in model mice to normal level.

\section{Effects of QWBZP on bacterial lactase genes structure in the intestinal mucosa}

PCA analysis was applied for OTUs results of bacterial lactase genes sequencing. Each point represented a sample, and the points with different colors belonged to the different groups. The closer the distance between two points was, the higher the similarity of gene sequence structure between two samples, and the smaller the difference was. It could be seen that the percentage contributed to variation of PC1 and PC2 was $99.99 \%$, and these provided

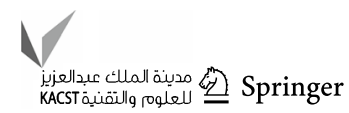


Fig. 1 Effects of QWBZP on the intestinal mucosa bacterial lactase genes diversity. $* p<0.05 ; * * p<0.01$
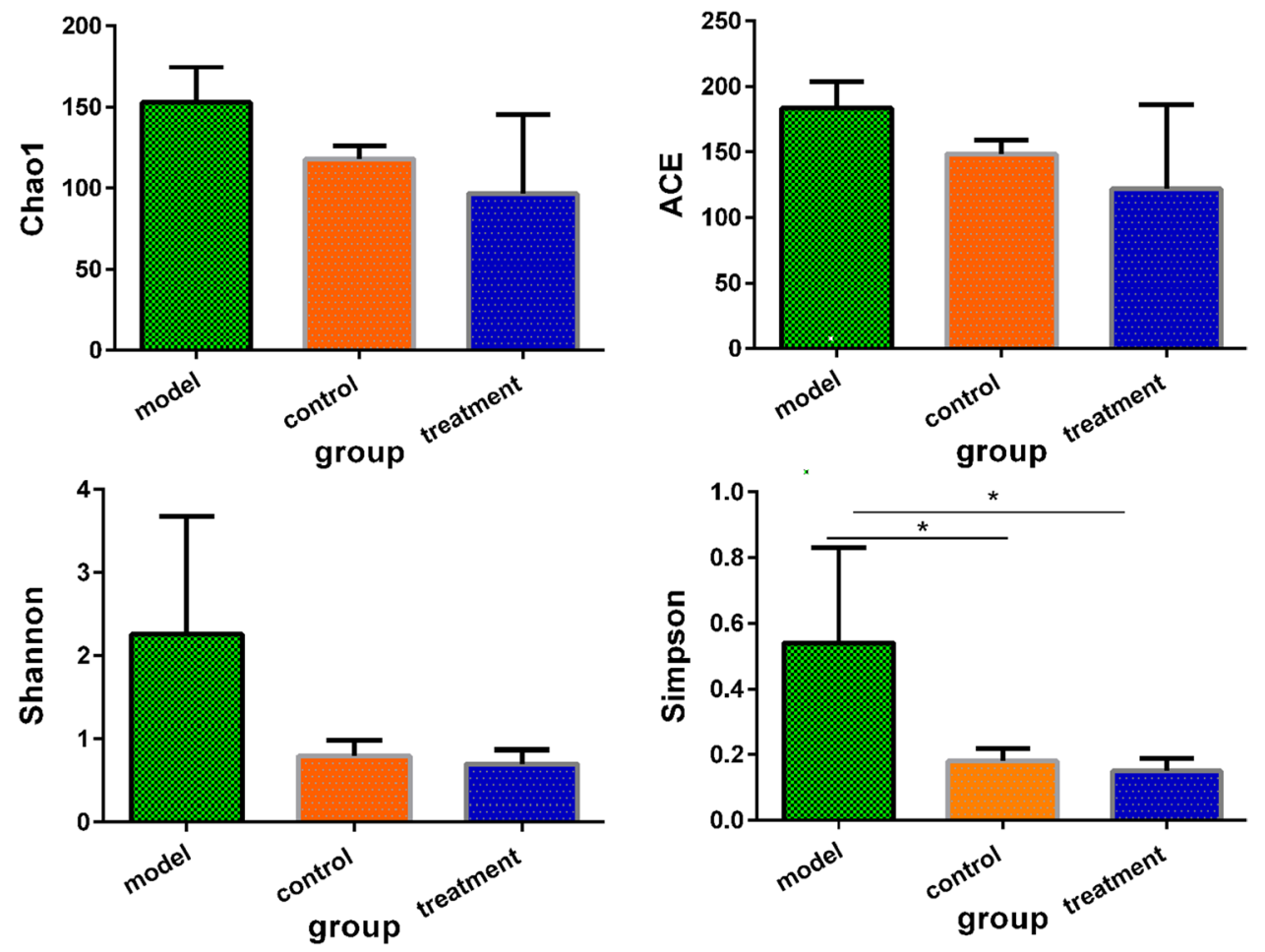

the vast majority of raw data information (Fig. 2a). The results also showed that samples between the control group and the model group were significantly separated, and the distance between the two groups was relatively great, indicating that antibiotic modeling had a significant impact on the structure of bacterial lactase genes in the intestinal mucosa. After treatment with QWBZP, the distance of samples was tightly concentrated between treatment and control groups compared to samples between treatment and model groups. These findings suggest that QWBZP has good curative effect on bacterial lactase genes in intestinal mucosa.

To further investigate the similarity of bacterial lactase genes, Hierarchical clustering was used based on UniFrac distance matrix. In particular, the distance length between samples in each group was measured. According to the similarity between samples, the shorter the branch length between two samples was, the higher the similarity between two samples. As shown from Fig. 2b, tlcm 1, tlcm2, tlcm3 and tlqm 2 are clustered into a category, tlmm 2 and tlmm 3 are clustered into a category, tlqm1, tlqm 3 and tlmm 1 are clustered separately. These results showed that the similarity of gene sequences from the control group was higher compared to the sequences from the model group, indicating that antibiotics may destroy the structure of intestinal mucosa bacterial lactase genes. After treatment with QWBZP, tlqm2 could be well grouped with the normal group, indicating that the difference of lactase genes sequence between normal and treatment group mice is small. However, tlqm 1 and tlqm3 are not clustered with the normal group, which may be related to individual differences in mice.

\section{Effects of QWBZP on bacterial lactase genes OTUs number in the intestinal mucosa}

Based on sequence homogeneity, the sequences with over 97\% similarity were aligned and grouped into individual OTUs, and the results were analyzed by Qiime software. There were 298, 435 and 254 OTUs expressed in mice from control group, model group and treatment group, respectively. Among them, 151 were identical (Fig. 3). It indicates that antibiotic increased the number of OTUs of bacterial lactase gene in intestinal mucosa, and they decreased significantly to normal level after treatment with QWBZP.

\section{Effects of QWBZP on bacterial lactase genes abundance in the intestinal mucosa}

The source and abundance of lactase gene in each sample were counted at the phylum and genus levels, respectively. At the phylum level, the difference in the proportion of lactase-producing bacteria between treatment and control groups was less than that between treatment and model groups. The intestinal mucosa bacterial lactase genes were mainly originated from Proteobacteria both in control and treatment group. After being induced by antibiotics, the relative abundance of Proteobacteria decreased and the abundance of unclassified bacteria increased. At the genus level, 

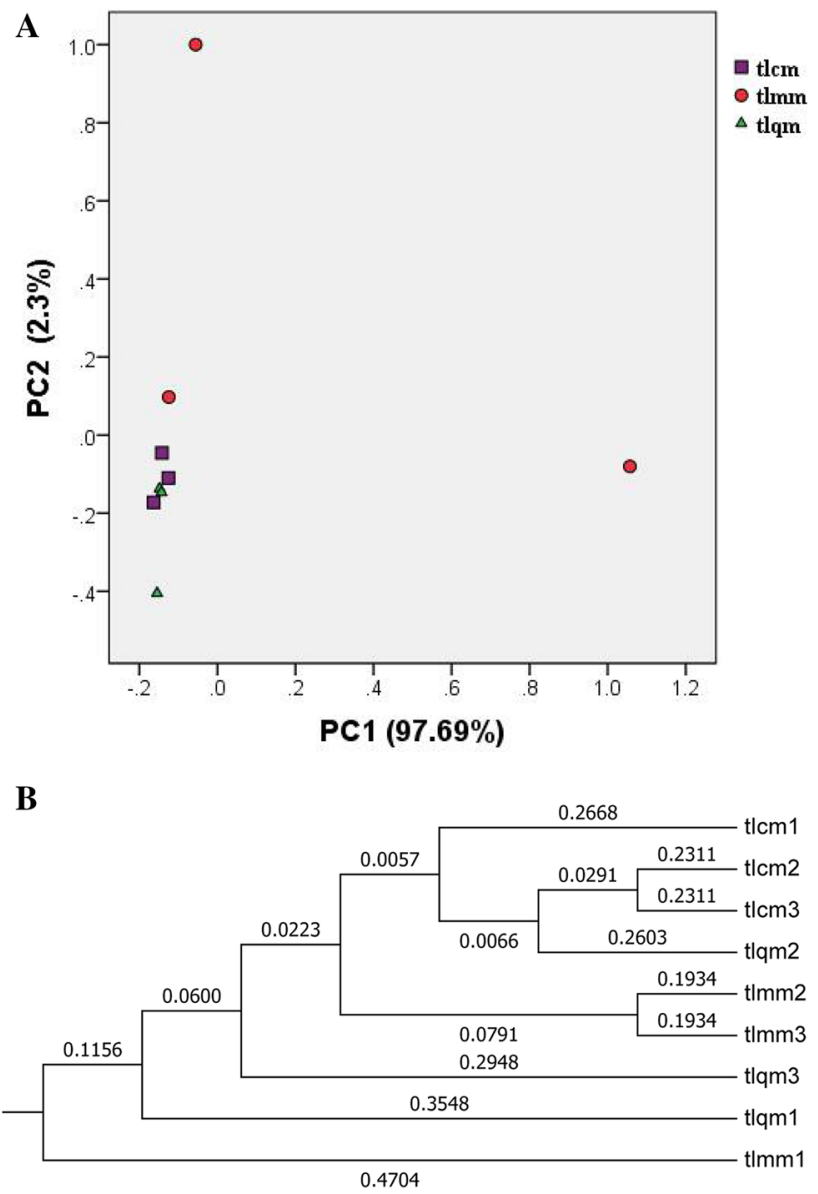

Fig. 2 Effects of QWBZP on the intestinal mucosa bacterial lactase genes structure. tlcm: control group; tlmm: model group; tlqm: treatment group

we got the same result. A total of 8 genera were detected among three groups, there were 5, 3 and 8 genera in control group, model group and treatment group, respectively, and 3 of them were identical. In addition, 5 of these genera were identical in treatment and control groups. The relative difference of genera in control and treatment groups was less than that in control and model groups. In comparison with control and treatment groups, model group increased the abundance of lactase gene originated from Citrobacter and unclassified bacteria, and reduced the abundance of Stenotrophomonas (Fig. 4).

To confirm our finding, further analysis was provided. In Fig. 4, the ordinate represents taxonomic units with significant differences between groups, and the abscissa shows the logarithm scores of the LDA difference analysis corresponding to the taxonomic units based on bar graphs and sorted by score values to describe the difference between groups. The different color of bar indicates the higher abundance sample corresponding to the taxonomic unit. The longer the bar chart length, the more the difference of taxonomic units

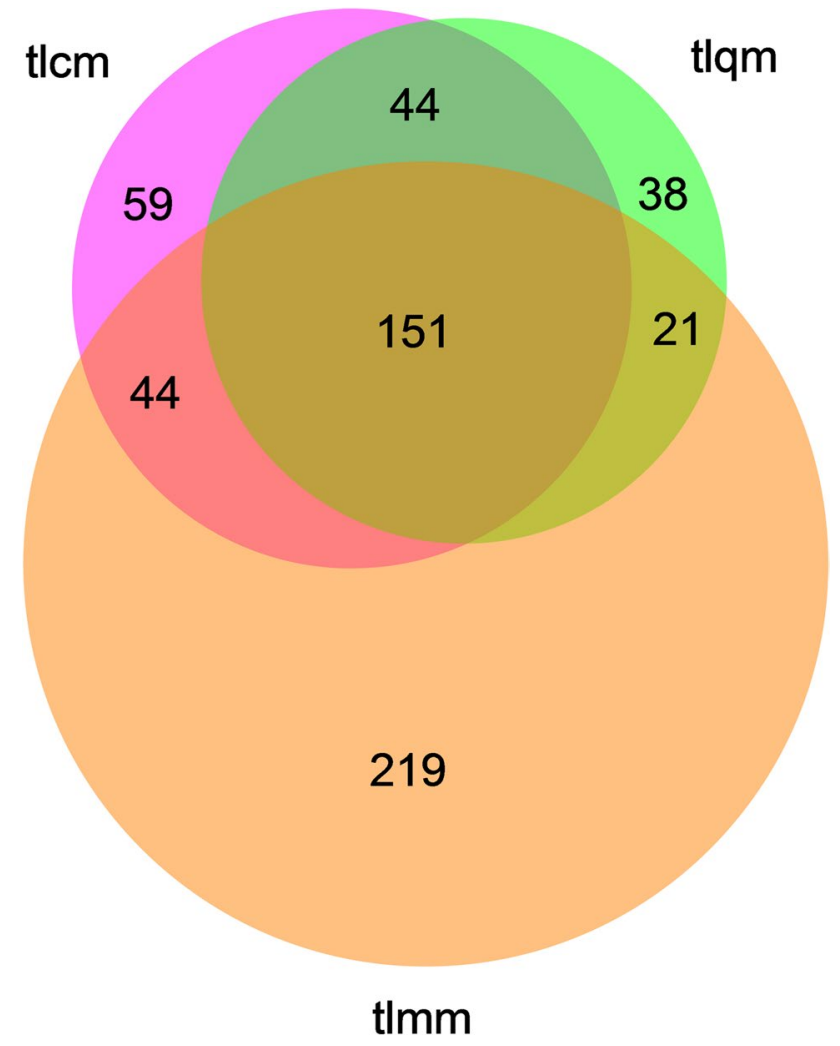

Fig. 3 Effects of QWBZP on the intestinal mucosa bacterial lactase genes OTUs number. tlcm: control group; tlmm: model group; tlqm: treatment group

became. As indicated in Fig. 4, the lactase gene abundance of bacteria was highly present in model group compared with that from control and treatment groups, and the abundance of Phyllobacteriaceae and Mesorhizobium in control group were significantly higher than those both in model and treatment groups. Furthermore, QWBZP increased the abundance of bacterial lactase genes from Lysobacter and Eukaryota.

\section{Effects of QWBZP on bacterial lactase genes similarity in the intestinal mucosa}

The difference based on the UniFrac distance value in different groups can be displayed by the box plots. The specific distribution characteristics of each group data can be presented according to median value, upper and lower quartiles, maximum and minimum values. The abscissa represents the comparison in intra-group or in inter-group, the ordinate indicates the corresponding distance value, and box size corresponds to the difference of sample gene sequence. The results showed that the difference in intersample was minimum in the control group, followed by the treatment group, and the difference was maximum in the model group. What's more, the difference in intra-group 

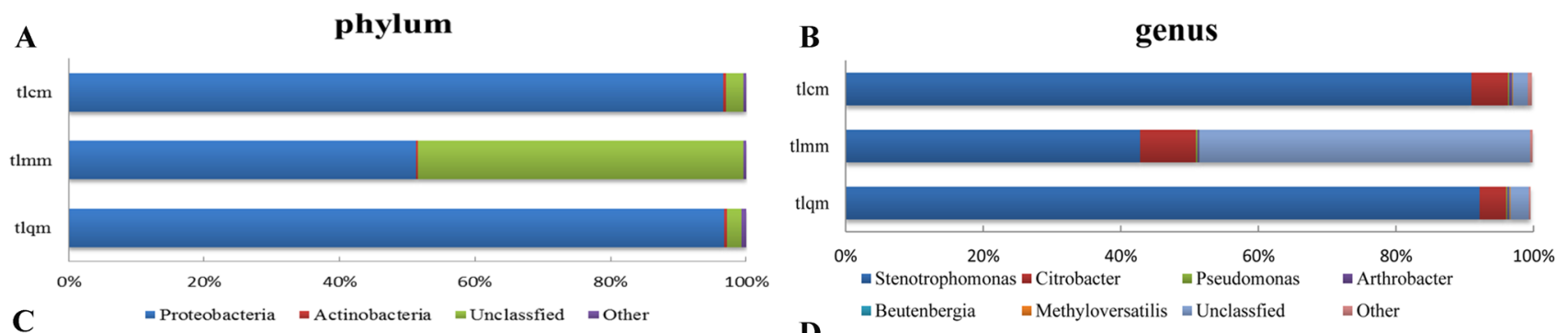

\begin{tabular}{|ccccc|}
\hline taxon & $\begin{array}{c}\text { relative } \\
\text { abundance }\end{array}$ & group & LDA Score & p-value \\
\hline Eukaryota & $\mathbf{2 . 1 7 6 7 6 4 1 5 9}$ & tlqm & $\mathbf{3 . 9 2 6 1 2 0 7 9 3}$ & $\mathbf{0 . 0 3 4 8 6 3 2 5 6}$ \\
\hline Lysobacter & $\mathbf{2 . 2 8 4 0 4 3 1 2 4}$ & tlqm & $\mathbf{3 . 5 7 7 7 9 7 0 3 7}$ & $\mathbf{0 . 0 3 4 8 6 3 2 5 6}$ \\
Phyllobacteriaceae & 1.988944724 & tlcm & $\mathbf{3 . 8 7 0 7 3 8 4 4}$ & $\mathbf{0 . 0 2 2 1 0 9 1 2 8}$ \\
\hline Mesorhizobium & 1.988944724 & tlcm & $\mathbf{3 . 9 1 9 3 5 2 2 1 2}$ & $\mathbf{0 . 0 2 2 1 0 9 1 2 8}$ \\
\hline Bacteria & 6 & tlmm & $\mathbf{4 . 5 2 6 1 0 9 7 1 7}$ & $\mathbf{0 . 0 3 4 8 6 3 2 5 6}$ \\
\hline
\end{tabular}

$\mathbf{D}$

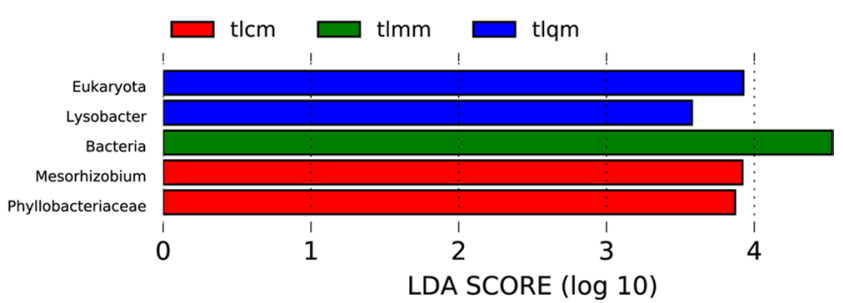

Fig. 4 Effects of QWBZP on the intestinal mucosa bacterial lactase genes abundance. tlcm: control group; tlmm: model group; tlqm: treatment group

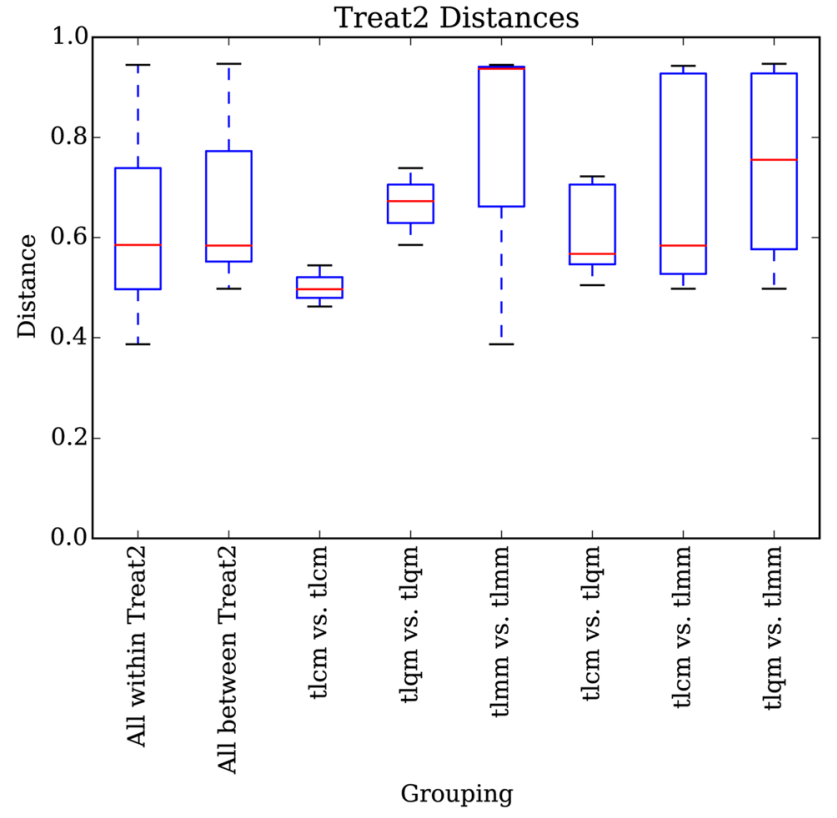

Fig. 5 Effects of QWBZP on the intestinal mucosa bacterial lactase genes similarity. tlcm: control group; tlmm: model group; tlqm: treatment group

was higher than that in inter-group (Fig. 5). It indicates that there was significant difference in genes sequence similarity between control and model groups. After treatment with QWBZP, lactase genes sequence in the treatment group was close to the sample in the control group, their difference was small, and their similarity was high, which suggested that the mice returned to normal.

\section{Discussion}

\section{QWBZP helped to recover the diversity of bacterial lactase genes in intestinal mucosa}

In recent years, molecular ecology research focusing on the functional gene diversity of encoding related enzymes has been rapidly developed, which provided a new starting point for understanding the ecological function of microorganisms from the perspective of functional genes, and attained more realistic mean in the ecological function of microorganisms using functional gene diversity including abundance and structure (Zhang et al. 2006; Yang et al. 2009). The current research aimed to investigate the diversity of intestinal microbiota used lactase gene and applied second-generation Miseq metagenome sequencing, which provided a new way for researchers to evaluate the effect of Chinese herbal compound on the diversity of intestinal microbiota at the molecular level. The results show that the $\alpha$-diversity index of bacterial lactase gene in QWBZP group was lower than model group and was similar to control group. We have got the same result in OTUs number, the number of OTUs (435) in the model group was significantly higher than that in the control group (298) and QWBZP group (254), and the OTUs number in QWBZP group was close to normal group. It indicated that treatment with QWBZP could help recover the diversity of bacterial lactase gene to normal level, and cure the dysbacterial diarrhea. These results are in sharp contrast to our previous study, the bacterial lactase gene diversity in the intestinal contents was not recovered after treatment with QWBZP (He et al. 2017b). A possible reason may be related to the different composition of intestinal microbiota between contents and mucosa. 


\section{QWBZP effectively restored the community structure of bacterial lactase- producing genes in intestinal mucosa}

The method PCA was applied for the analysis of bacterial community structure. From our results, the distribution was relatively concentrated in both control and QWBZP groups, the sample distance was close, and the similarity of gene structure was high. While in model group, the sample distance was relatively great, and the difference was larger in inter-group. Furthermore, the distance was also far way between model group and control/QWBZP group, indicating the poor similarity between model and other two groups.

To further investigate the homogenous bacterial lactase gene, HC was used. The results showed that QWBZP group was clustered with control group, while the model group was classified as a single group. In box plot, the size was smaller both in control and QWBZP groups, but larger in model group. Moreover, the box size was obviously smaller in inter-group and larger in intra-group. These findings suggest that antibiotic modeling has destroyed the structure of bacterial lactase genes and there was significant difference in lactase genes between model and control/QWBZP groups. These results are consistent with our previous study that antibiotic modeling changed the structure of bacterial lactase genes (Long et al. 2017b, 2018). In addition, the difference in lactase genes between control and QWBZP group was small, and the similarity in gene structure was high, suggesting that treatment with QWBZP could help to restore the community structure of bacterial lactase-producing genes to normal level. This result is superior to the curative effect of QWBZP on bacterial lactase gene in the contents (He et al. 2017b). We hypothesize that this is related to the repair effect of QWBZP on the structure in the intestinal mucosa of mice with dysbacterial diarrhea (Zhang et al. 2013; Liu et al. 2014).

\section{QWBZP effectively regulated the abundance of bacterial lactase genes in intestinal mucosa}

The species abundance of phylum and genus were compared among three groups. In comparison with control group, the composition and abundance of species was similarity to QWBZP group at the phylum and genus levels. The model group decreased the abundance of lactase gene originated from Proteobacteria and Stenotrophomonas, and increased many unclassified lactase genes. In specific taxonomic units, antibiotics modeling increased the abundance of Bacteria, and the abundance of Lysobacter and Eukaryotawas increased after treatment with QWBZP.

In our previous study, the genera of lactase detected in the intestinal contents were far beyond these in the intestinal mucosa, suggesting that there are more lactase-producing strains in the intestinal contents. After treatment with QWBZP, the number of bacterial lactase genes in the intestinal contents of model mice was significantly decreased $(P<0.01)$. QWBZP effectively restored some lactase gene species or certain mutant genes $(\mathrm{He}$ et al. 2017b). In our opinion, some possible reasons for this could be the difference in the main source of lactaseproducing strains between contents and mucosa, the stability of bacterial colonization in intestinal mucosa, and the function of mucosal self-immunity (Long et al. 2018).

In summary, antibiotics destroyed the structure of bacterial lactase genes in the intestinal mucosa, and increased their diversity. After treatment with QWBZP, the diversity of bacterial lactase genes in intestinal mucosa restore to normal level. Our study suggests that the probable mechanism of QWBZP on dysbacterial diarrhea would be the recovery of some key mucosal bacterial lactase-producing genes diversity and structure.

Acknowledgements Thanks are extended to the National Natural Science Foundation of China (81573951).

\section{Compliance with ethical standards}

Conflict of interest The authors declare that they have no conflict of interest.

Ethical approval Ethical approval was obtained from the Animal Ethics and Welfare Committee of Hunan University of Chinese Medicine.

\section{References}

Cao YJ, Zhang YS, Xu LZ, Mi XS, Wang H (2017) Prevention of antibiotic-associated diarrhea with microecological modulators. Chin J Nosocomiol 17:17-19

Carter SL, Attel S (2013) The diagnosis and management of patients with lactose -intolerance. Nurse Pract 38:23-28

Guo KX, Tan ZJ, Xie MZ, She Y, Wang XH (2015) The synergic effect of ultra-micro powder Qiweibaizhusan combined with yeast on dysbacteriotic diarrhea mice. Chin J Appl Environ Biol 21:61-67

He L, Long CX, Liu YJ, Xiao NQ, Tan ZJ (2017a) Regulative effect of Chinese herbs on intestinal digestive enzyme activities. J Chin Med Mater 40:1984-1987

He L, Liu YW, Guo YF, Shen KJ, Hui HY, Tan ZJ (2017b) Diversity of intestinal bacterial lactase gene in antibiotics-induced diarrhea mice treated with Chinese herbs compound Qi Wei Bai Zhu San. 3 Biotech 8:4

Jin L, Yang XH, Ren JL, Li JL, Guo XY, Cao P, Wang Z (2012) Effect of dietary compound probiotics on disaccharidase in small intestine mucosa of layer breeders. China Poultry 34:14-17

Juajun O, Nguyen TH, Maischberger T, Iqbal S, Haltrich D, Yamabhai M (2011) Cloning, purification, and characterization of $\beta$-galactosidase from Bacillus licheniformis DSM 13. Appl Microbiol Biotechnol 89:645-654

Liu H, Sun T (2014) Research progress of intestinal dysbacteriosis. Med Recap 20:468-471

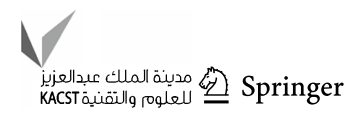


Liu QS, Xu XH, Liu H, Tan ZJ (2014) Effects on intestinal villi and crypts in flora diarrhea mice by Qiweibaizhu powder. Chin Med Mod Dis Educ China 12:154-155

Long CX, He L, Liu YJ, Hui HY, Tan ZJ, Li DD (2017a) Universal primer for analysis of the diversity of intestinal bacterial lactase gene. Chin J Appl Environ Biol 23:758-763

Long CX, He L, Guo YF, Liu YW, Xiao NQ, Tan ZJ (2017b) Diversity of bacterial lactase genes in intestinal contents of mice with antibiotics-induced diarrhea. World J Gastroenterol 23:7584-7593

Long CX, Liu YW, He L, Tan QQ, Yu ZZ, Xiao NQ, Tan ZJ (2018) Bacterial lactase genes diversity in intestinal mucosa of mice with dysbacterial diarrhea induced by antibiotics. 3 Biotech 8:176

Ma FL, Zhang XL, Guo JJ, Shen XM (2014) Research progress of gastrointestinal mucosal protective effect of Chinese medicine. Medicinal Plant 5:1-4

Ma J, Tang XY, Chen QH, Liu MF (2017) Advances in research on lactase and its influencing factors in animal. Feed Industry 38:15-17

Mahaffee WF, Kloepper JW (1997) Temporal changes in the bacterial communities of soil, rhizosphere, and endorhiza associated with field-grown cucumber (Cucumis sativus L.). Microb Ecol 34:210-223

Peng HZ, Ren LH (2011) Relationship between antibiotics associated diarrhea and lactase intolerance. Chin Genral Prac 14:2999-3006

Peng XX, Shu L, Tao H, Cao R, Tan ZJ (2014) Clinical application of addition and subtraction of Qiweibaizhusan for treatment of infantile diarrhea. WCJD 22:1345-1350

Pitta DW, Pinchak E, Dowd SE, Osterstock J, Gontcharova V, Youn E, Dorton K, Yoon I, Min BR, Fulford JD (2010) Rumen bacterial diversity dynamics associated with changing from bermudagrass hay to grazed winter wheat diets. Microb Ecol 59:511-522

Pitta DW, Parmar N, Patel AK, Indugu N, Kumar S, Prajapathi KB, Patel AB, Reddy B, Joshi C (2014) Bacterial diversity dynamics associated with different diets and different primer pairs in the rumen of Kankrej cattle. PloS One 9:e111710

Ramette A (2007) Multivariate analyses in microbial ecology. FEMS Microb Ecol 62:142-160

Rhimi M, Aghajari N, Jaouadi B, Juy M, Boudebbouze S, Maguin E, Haser R, Bejar S (2009) Exploring the acidotolerance of betagalactosidase from Lactobacillus delbrueckii subsp. bulgaricus: an attractive enzyme for lactose bioconversion. Res Microbiol 160:775-784

Ruchkina IN, Fadeeva NA, Parfenov AI, Shcherbakov PL, Gubina AV, Poleva NI, Khomeriki SG, Chikunova BZ (2013) The role of small bowel microflora in the development of secondary lactase deficiency and the possibilities of its treatment with probiotics. Ter Arkh 85:21-26

Shannon CE (1997) The mathematical theory of communication.1963. MD Comput 14:306-317

Sun J, Lin J, Parashette K, Zhang J, Fan R (2015) Association of lymphocytic colitis and lactase deficiency in pediatric population. Pathol Res Pract 211:138-144
Tan ZJ, Zhang HL, Zhou SN, Yu WY, Zeng A, Cai Y, Cai GX (2013) Change of intestinal microbes in dysbacteriosis-modeled mice treated with ultra-micro powder of Qiweibaizhusan. Chin J Appl Environ Biol 19:449-453

Tran CD, Cool J, Xian CJ (2011) Dietary zinc and metallothionein on small intestinal disaccharidases activity in mice. World J Gastroenterol 17:354-360

Vandenplas Y (2015) Lactose intolerance. Asia Pac J Clin Nutr 24:S9-S13

Wiecek S, Wos H, Radziewicz Winnicki I, Komraus M, Grzybowska Chlebowczyk U (2014) Disaccharidase activity in children with inflammatory bowel disease. Turk J Gastroenterol 25:185-191

Wu H, Zhou SN, Guo C, Tan ZJ, Cai GX, Zeng A, Zhang HL (2012) A metagenome DNA extracting method of intestinal flora in mice for molecular diversity analysis based on PCR technology. Chin J Microecol 24:648-651

Xiao XY, Zhao XP, Tang B, Wang H, Yin KK, Peng XX, Guo KX, Tan ZJ (2015) The effect of Qiweibaizhusan on blood of diarrheal mice with dysbacteriosis. Microbiol China 42:325-331

Yang N, Zhao J, Wang YQ, Zeng RY (2009) Diversity of dissimilatory sulfite reductase gene in deep sea sediment of the West Pacific "warm pool". Acta Oceanol Sin 31:78-86

Yao MZ, Chen ZJ, Xu L (2012) Study on effect of traditional Chinese medicine additive on digestive enzyme activity of Hainan Wenchang chicken. China Anim Husb Vet Med 39:82-85

Zeng A, Zhang HL, Tan ZJ, Cai Y, Cai GX, Zhou SN (2012) The construction of mice diarrhea model due to dysbacteriosis and curative effect of ultra-micro Qiweibaizhusan. Microbiol China 39:1341-1348

Zhang J, Zhang HW, Li XY, Su ZC, Zhang CG (2006) Soil microbial ecological process and microbial functional gene diversity. Chin J Appl Ecol 17:1129-1132

Zhang XL, Xu QQ, Wang LY, Huo XQ, Cao LZ, Chen LG, Ren YH, Dong SS (2009) The influence of sijunzitang on the lactase activity in diarrhea mice intestinal mucosa. Chinese Society of Animal Husbandry and Veterinary Society Proceedings. 88

Zhang XL, Wang YC, Xu QQ, Wang LY, Huo XQ, Cao LZ, Zhang YH, Dong SS (2010) The influence of decoction of compound Radix pulsatillae on the lactase activity in diarrheal mice intestinal mucosa. J Agric Univ Hebei 33:99-102

Zhang HL, Zhou SN, Cai Y, Guo KX, She Y, Tan ZJ, Cai GX (2013) The effect of ultra-micro powder Qiweibaizhusan on the mucous membrane of small intestine of diarrheal mice with dysbacteriosis. Chin J Microecol 25:9-13

Zhang HL, Cai Y, Tan ZJ, Zhou SN, Guo KX, She Y, Cai GX (2014) Effects of ultra-micro powder Qiweibaizhusan on metabolism diversity of intestinal microflora in diarrhea mice with dysbacteriosis. Chin J Appl Environ Biol 20:93-100 